\section{The Hard Truth about Soft Skills}

By

Tres Bishop, University of South Florida

T his article provides value to hiring managers and academics by positing a conceptual model that could potentially revitalize the methods employed to train, coach, interview, and hire new college graduates. The model shows that success (measured as employee productivity) is the summation of education (hard skills), plus

Many hiring managers have pondered the mysteries of recruiting a highly productive new employee who can hit the ground running on day one. Soft skills in a new employee's portfolio may be the missing link. experience (time in one's domain), plus soft skills. Each of the variables (employee produc- tivity, education, experience, and soft skills) is moderated by cost and organizational culture. Further, the author argues that these soft skills are the preeminent factor among the three independent elements for new employee success. It turns conventional wisdom on its head by declaring that it is soft skills development that is the single most important predictor of a new employee's success in a world obsessed by hard skills.

Keywords: Soft Skills, Hard Skills, Employee Productivity, Education, Experience, Cost, Culture. 


\section{Introduction}

John Roberts did not like to solve the same problem twice. As an engineer and relative expert in efficien$\mathrm{cy}$, the thought of expending valuable time and resources on a problem that had been previously solved irked him. And yet here he was again, solving the exact same problem he had seen numerous times as a leader and a hiring manager. His team had reached a breaking point. As the quantity of purchase orders increased, so did the workload and expectations levied on his team. To be sure, this was a good problem to have but it was a problem nonetheless. Recognizing the issue, Roberts received permission from the powers that be to recruit a new employee to his team with the caveat to keep expenses as low as possible. To maximize this constraint, the obvious solution was to bring a new graduate on board. There were many advantages to this strategy. Typically, new engineering graduates had sound problem solving abilities, were up to date on the latest methods or procedures in their chosen domain and, usually, were virtual wizards in the application of technology to business problems. What the new graduates lacked were the soft skills that made the engine of business run smoothly. That was why the Director of $\mathrm{Hu}$ man Resources was in his office this morning. One of Roberts' new graduates had hit "reply all" on a corporate wide email, and the specifics of the email had offended some of her colleagues. This was an all too familiar and almost predictable episode. Roberts couldn't help but wonder why this issue kept repeating itself. Nearly all of the offenders that Roberts had personally known in the previous decade had sterling reputations and impeccable credentials from some of the finest universities in the United States. "Wasn't this a topic that was covered at the college level?", he asked to no one in particular. If not, why? What other solutions could be created to help bridge the gap from college to the working world, and help new graduates contribute on dayone?

Roberts was the recently hired Director of Quality Assurance for Communications Services International (CSI) in Melbourne, Florida. His background included approximately 12 years of various leadership positions in the aerospace and defense industries with a specific focus on innovation and leadership. Roberts' educational background had been engineered for the purpose of high impact leadership, and included an undergraduate degree in industrial and systems engineering as well as master's degrees in business administration and engineering management. The vast majority of Roberts' career had been in big business where resources were plen- tiful, decisions to change were slow, and one project rarely made or broke the company. The situation couldn't be more different now. He had made the decision to transition to a small enterprise for precisely that reason. In a small company, there was a constant battle for resources, decisions for change came at a rapidity that was electrifying for someone who had grown up in the bureaucracy of corporate America, and leadership skills, in particular, were valued at a premium. At CSI, Roberts would have the opportunity to build a team from the ground up, and that thought simultaneously filled him with exhilaration and dread. At last, Roberts had the opportunity he had been looking for--now he had to deliver, and the choice of what problem to investigate would be critical to that effort.

As an engineer, Roberts was a trained problem solver. As a leader, he was committed to maximizing the performance of his team and organization. Shaking hands as the Director of HR left his office, Roberts thought to himself, "I have just found the next problem that must be solved."

\section{Review of Research}

This study began as an inductive research project in which the author observed the same phenomenon repeatedly in the workplace. Specifically, new graduates from across the academic spectrum were not adequately prepared to enter the workforce in terms of soft skills development which in turn impacted that individual's productivity and/ or performance level. How could this be? These new graduates were, for the most part, graduates from respected universities in the southeastern United States. In an effort to investigate what was known on the topic, the author used the library resources at the University of South Florida, specifically ABI/Inform database and Google Scholar. The author used the search terms "soft skills development," and "new college graduates." ABI/Inform returned 141 articles once confined to only peer reviewed articles that were published in the last year. All of these articles were scanned, and a total of 10 were downloaded for further review based on relevance to the research question. Google Scholar was then searched using the same terms. Twenty-five additional articles were scanned and five downloaded for further review again based on the relevance to the research question. Google Scholar was also utilized to build the conceptual model. The search terms used were, "employee productivity and education," "employee productivity and experience," and "employee productivity and soft skills" which yielded over 14,600 results 
of which 70 articles were scanned and seven downloaded for review using the same method previously mentioned. Two additional articles were included based on recommendations from peer review. The total number of resources used for this study was 24 .

In Britain, it is reported that the work force is facing a soft skills deficit which threatens productivity and could have major financial implications for the UK economy. A report published by Development Economics Ltd. suggested that by 2020 over half a million workers will be significantly held back by a lack of soft skills, and that this particular issue is forecasted to affect all industry sectors (Clarke \& Clarke, 2016). That statement begs the question: What soft skills are important? Ultimately, there is not a consensus as to what specific skills should be developed in order to produce workplace ready graduates. For the large part, the primary stakeholders in this arrangement, namely new graduates, faculty, and prospective employers do not agree on which skills are the most important to develop (Rosenberg, Heimler \& Morote, 2012). For instance, in the domain of computer science, the most sought after soft skills appear to be related to written and verbal communication (Radermacher \& Walia, 2013). Interestingly, communication skills were not deemed as significant for new graduates to possess by employers in the United States, Europe, and Morocco (El Mansour \& Dean, 2016). In another study, communication was deemed to be important, but not as important as flexibility and adaptability (Vendolska, 2016). Even when the skills were identified, there was no guarantee that the most important skills would be effectively measured by potential employers. A study conducted in Hong Kong found that while employers viewed conscientiousness as the most ideal skill for effective performance, it was difficult to measure, and that the more easily measured extraversion factor was used to make hiring decisions. This of course, led to the conclusion that successful applicants may not be ideal employees (Moy, 2006).
After reviewing the research, one obvious question remains: Why is there no consensus as to what constitutes soft skills? The reason may be that only recently has the focus of educators and employers shifted from cognitive abilities, (i.e., hard skills) to the more ambiguous soft skills (Kyllonen, 2013). According to Investopedia.com, hard skills are specific, teachable abilities that can be defined and measured, such as: typing, writing, math, reading, and the ability to use software programs. These hard skills are the skills that institutions of higher learning excel at imparting to eager students. By contrast, soft skills are less tangible and harder to quantify, such as etiquette, getting along with others, listening, and engaging in small talk. These skills are often thought of as a part of one's character and until relatively recently, have received scant attention from institutions of higher learning. Fortunately, this has begun to change as universities and the collegiate community have recognized that to be competitive in an ever-changing world, soft skills are increasingly in demand (Clarke \& Clarke, 2016). In an effort to meet that demand, there has been a call for educators at the university level to fill the gap by embedding soft skills training opportunities into the more traditional hard skills

\section{Soft skills are less tangible, such as etiquette, getting along with oth- ers, listening, and engaging in small talk.} courses (Schulz, 2008). Although there is a growing body of research that points to the need for soft skill development, alarmingly, there is not--as of this writing--a single list that defines exactly what those soft skills should be. However, the themes of communication, both written and verbal, along with the ability to effectively function within a team, a desire to learn, being teachable, work ethic, leadership, motivation, flexibility, creativity, problem solving, and an overall positive attitude are routinely mentioned among the most desired soft skills that are lacking from recent graduates (Andrews, 2008; Finch, 2013; Finch, 2016; Jordan, 2016; McMurray, 2016; Radermacher, 2013; Robles, 2012; Schultz, 2008; Vendolska, 2016).

If we are to use the list in Table 1 as a launching pad for soft skill development, then the following ques-

Table 1: Common Soft Skills

- Written communication

- Verbal communication

- Teamwork

- Desire to learn

- Teachable

- Creativity
- Work ethic

- Leadership

- Motivation

- Flexibility/Adaptability

- Positive attitude

- Problem solving 


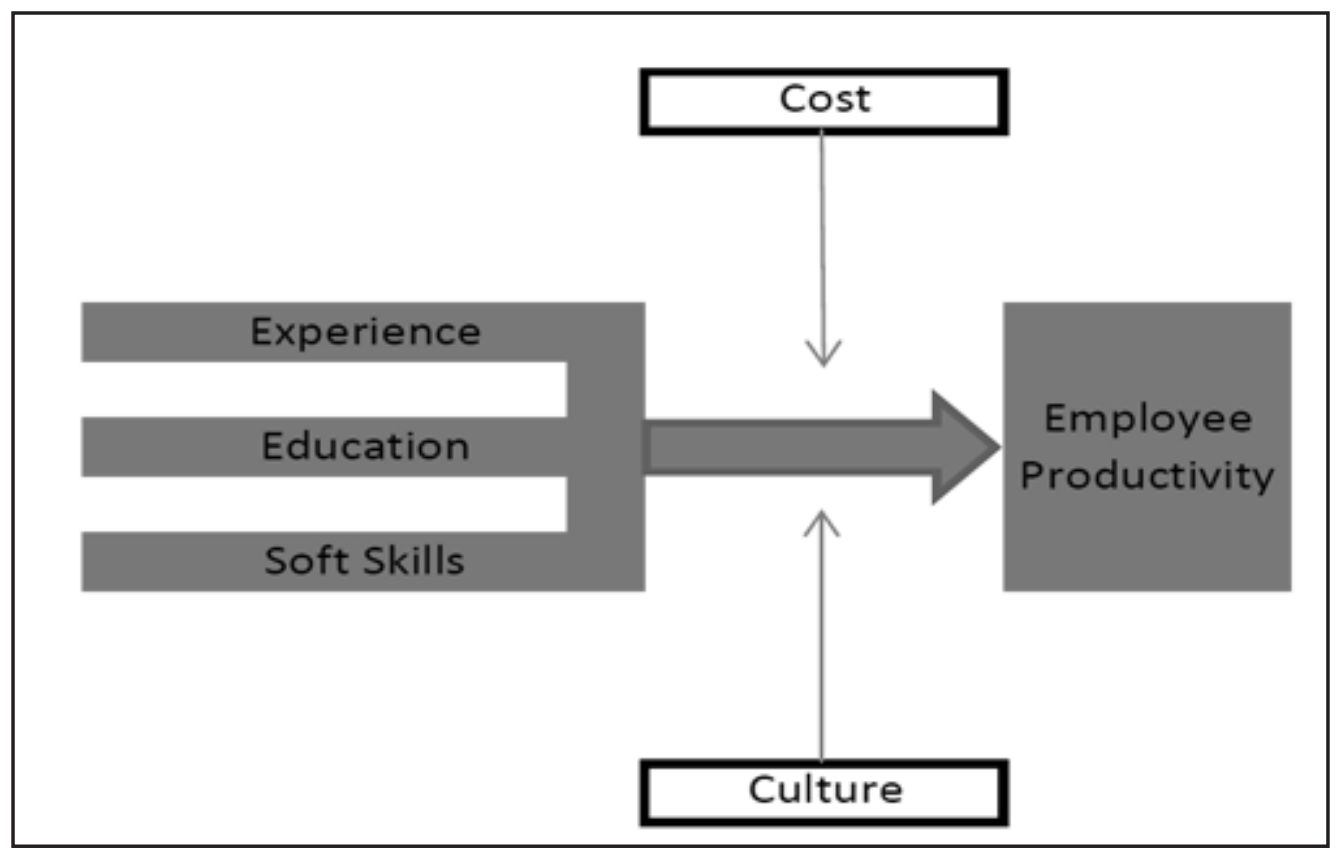

Figure 1: Employee Productivity Model

tions remain:

- What factors affect a new employee's ability to be productive?

- What level of competency for these factors is required by industry?

- What level of competency for soft skills is required by industry?

- What can be done to achieve that level of competency?

- How does an employer best assess those competencies?

- Who is best prepared to lead that effort? This article will focus primarily on the first question and briefly touch on the last. The other questions will be left for further research opportunities.

\section{The Proposed Theory}

For most organizations, the primary goal when hiring a new team member is to match the right person with the right opportunity. A possible method of measurement that can be applied to determine if the desired outcome was achieved is to measure the new employee's productivity after a specified time-period. This article argues that an employee's productivity, (i.e., success) can be measured as follows as shown in Figure 1.

As the graphic above shows, an employee's productivity is the output of the education, plus the experience, plus the soft skills of that new employee. Thus, the employee's productivity is the dependent variable and education, experience, and soft skills are independent variables. Cost and culture are defined as moderating variables as they influence the relationship between the independent and dependent variables.

By education the author means the educational attainment of that individual. For the purposes of this article, education will be understood to be the new employee's college degree (AS, BS, MS, $\mathrm{PhD}$, etc.) or lack thereof. The employee's productivity will be positively impacted by a higher level of educational attainment. Likewise, an employee with no educational background will negatively impact productivity. For example, with all other skills levels being equal, productivity will be expected to be greater for an employee who possesses a $\mathrm{PhD}$ versus no college degree.

Experience will be the new employee's work experience in a particular field of practice (Supply Chain, Operations, Engineering, etc.). Productivity will be expected to be positively related to greater experience and negatively related to no experience. Intuitively, this makes sense. One would expect an employee whom had been working in a particular field for a specified period of time to acquire skills along the way that would increase his functional job knowledge which would increase his productivity. This is the primary reason why, in most cases, more experienced workers are more highly compensated (Holzer, 1990).

Soft skills will be defined as previously described in the preceding section namely: communication, both written and verbal, the ability to effectively function within a team, a desire to learn, being teachable, work ethic, leadership, motivation, flexibility, creativity, problem solving, and an overall positive attitude. Soft skills will be expected to be positively related to productivity. The absence of the soft skills 
defined above will have a negative impact on overall employee productivity:

- $\mathrm{H}_{0}=$ Soft skills have no impact on a new employee's productivity

- $\mathrm{H}_{\mathrm{a}}=$ Soft skills have a positive impact on a new employee's productivity

The moderating variable of cost can influence the relationship between the independent and dependent variables. It is a common practice in industry to "throw money" at a problem to make it go away. In the context of this article, this means that one could theoretically increase an employee's productivity by increasing the cost to acquire any of the 3 independent variables. For example, a hiring manager could hire an engineer with a bachelor's degree, and an average amount of soft skills development, but require 10 years of related experience. That increase in experience would likely increase the cost of hiring that specific employee. For the purposes of this article, we will hold cost as a constant.

The moderating variable of culture (defined as organizational culture) can also influence the relationship of the independent and dependent variables. In the context of this article, culture will be held as a constant. In future studies, this relationship will be examined in depth.

This article argues a new employee's soft skill development is the single most important predictor of that employee's future productivity or success at work. When hiring a new employee, training is a given. That specific training can range anywhere from a day to 6 months or more, depending on the determined job function and maturity of the hiring organization. As Carol Dweck describes in the book Mindset, in a growth mindset, people believe that their most basic abilities can be developed through dedication and hard workbrains and talent are just the starting point. This view creates a love of learning and a resilience that are essential for great accomplishments (Dweck, 2008). Sal Khan, the founder of Khan Academy, a nonprofit that provides free on-line training on a variety of educational subjects, puts it even more succinctly when he says, "You can learn anything." Therefore, the author proposes that soft skills, that can and should be measured in job interviews, are the single most important factor and predictor of future success when hiring new employees.

\section{Applications of the Theory}

This proposed theory and conceptual model have many practical applications that could be utilized for practitioners and academics alike. In the academic community, this model could be added to a growing body of research that asserts soft skills are at least as important (if not more important) in hiring decisions. Opportunities abound for innovative thinkers in academia who, based on this and similar research, develop programs to inculcate soft skills development into the normal curriculum. Perhaps the most direct application of this model is for the practicing hiring manger. This professional could use the model as a basis to develop interview questions and situations targeted to measure the soft skills enumerated in previous sections. The hiring manager could then use those questions and situations in actual interviews, and monitor the performance levels of the new employee. More forward-thinking practitioners may even use this model as a basis to develop specialized training courses or services that could serve as a bridge from college to the working world.

\section{Discussion}

We live in a world where potential employers are increasing expecting new graduates to be "employment ready"; i.e., equipped with the necessary skills and competencies to make a meaningful contribution on day one (Andrews \& Higgins, 2008). This article is an attempt to advocate the view that the presence of soft skills is the key element that determines a new employee's productivity. The proposed model claims that employee productivity is the sum of a new graduates' education, experience, and soft skills development. All three of these attributes are important and more of each one positively impacts productivity while the absence or degradation of any one of these attributes can negatively affect productivity. However, in today's knowledge economy, soft skills are now more than ever a critical aspect to getting things done. Nearly all seasoned professionals can recall working with or for a brilliant colleague who was blessed with exceptional technical ability (education) and really knew the ins and outs of the product or market (experience), but ultimately failed because of a lack of one or more of the soft skills, mentioned above. It is much more difficult for most of us to recall the similar failure of a person who exceled in terms of soft skills, and lacked the other 2 elements. This is because we live and work in a world where success is rarely an individual achievement. Steve Jobs did not create Apple by himself even though he became the embodiment of that iconic company, no more than Mark Zuckerberg created Facebook by himself. Both had talented, motivated people surrounding them that could work together for the common goal of changing the world. While we may not always be trying to change the world, 
we do want to make sure that our teams operate as efficiently and productively as possible. One way to ensure this is to make hiring decisions based more on soft skills than hard skills. In the end, hard skills can be taught, and it is much easier and less expensive to teach a person who is motivated to learn, than someone who is not.

A possible exception to this proposed theory is where significant technical or scientific knowledge is required. For example, the practice of medicine would not always be applicable to the constraints of the theory. No matter how strong a person's soft skills, one would presumably want a surgeon who possessed the requisite scientific knowledge to perform the surgery. However, the author would argue that not all surgeons are created equal, and all other attributes being the same, one who has acquired soft skills would be more productive and successful.

\section{Future Research}

There are many interesting avenues that could be explored related to this topic. The most direct is to test the model developed in this article in a quantitative study using a survey or related tool. Additionally, one could explore the role human resources plays in working with hiring managers to build a profile or job description that addresses key soft skills relevant to each position or to the organization as a whole. Another approach, could be to explore how the model applies to organizations of different sizes. Furthermore, if an employee is hired for technical ability alone, what are the most successful strategies to address the soft skills gap, and who (academic institutions or private practice) is more prepared to offer the best solution?

\section{Conclusions}

This article is an attempt to advocate the view that soft skills are the vital characteristic that should be sought after when hiring new college graduates, and that the presence of these soft skills will be the most important predictor of employee productivity. Prior research has shown that there is a fast approaching point in time where the vast majority of workers will have a deficit in terms of soft skills development. Research conducted by The Protocol School of Washington DC, in conjunction with Harvard University, the Carnegie Foundation and the Stanford research Institute reveal that technical skills and knowledge account for about 15 percent of the reason an individual gets a job, keeps a job, and advances in that job. The remaining 85 percent of job success is based on an individual's soft skills (Rao, 2014). Therefore, one of the most effective methods for hiring managers to best position their organizations and companies for future success is to hire new employees primarily based on soft skill development.

\section{Review}

This article was accepted under the constructive peer review option. For futher details, see the descriptions at:

http://mumabusinessreview.org/peer-review-options/

\section{References}

Andrews, J., \& Higson, H. (2008). Graduate employability, 'soft skills' versus 'hard' business knowledge: A European study. Higher education in Europe, 33(4), 411-422.

Clarke, M., \& Clarke, M. (2016). Addressing the soft skills crisis. Strategic HR Review, 15(3), 137-139.

Dweck, Carol S. (2008) Mindset: The new psychology of success. New York: Ballantine Books.

El Mansour, B. and Dean, J.C. (2016) Employability skills as perceived by employers and university faculty in the fields of human resource development (HRD) for entry level graduate jobs. Journal of Human Resource and Sustainability Studies, 4, 39-49. http://dx.doi.org/10.4236/jhrss.2016.41005

Finch, D. J., Hamilton, L. K., Baldwin, R., Zehner, M., (2013), An exploratory study of factors affecting undergraduate employability, Education \& Training, 55 (7), 681-704. https://doi.org/10.1108/ET-072012-0077

Finch, D. J., Peacock, M., Levallet, N., \& Foster, W. (2016). A dynamic capabilities view of employability. Education + Training, 58(1), 61-81. https://doi.org/10.1108/ET-02-2015-0013

Holzer, H. J. (1990), The determinants of employee productivity and earnings. Industrial Relations: A Journal of Economy and Society, 29, 403-422. doi:10.1111/j.1468-232X.1990.tb00761.x

Jordan, C., \& Bak, O. (2016). The growing scale and scope of the supply chain: A reflection on supply chain graduate skills. Supply Chain Management, 21(5), 610-626.

Kyllonen, P.C. (2013) Soft skills for the workplace. Change: The Magazine of Higher 267 Learning, 45(6), 1623.

McMurray, S., Dutton, M., McQuaid, R., \& Richard, A. (2016). Employer demandsfrom business graduates. Education + Training, 58(1), 112-132. 
Moy, J. M. (2006). Are employers assessing the right traits in hiring? Evidence from Hong Kong companies. The International Journal of Human Resource Management, 17(4).

Radermacher, A., \& Walia, G. (2013, March). Gaps between industry expectations and the abilities of graduates. In Proceeding of the 44th ACM technical symposium on Computer science education (pp. 525530). ACM.

Rao, M. S. (2014). Enhancing employability in engineering and management students through soft skills. Industrial and Commercial Training, 46(1), 42-48.

Robles, M. M. (2012). Executive perceptions of the top 10 soft skills needed in today's workplace. Business Communication Quarterly, 75(4), 453-465.

Rosenberg, S., Heimler, R., \& Morote, E. S. (2012). Basic employability skills: a triangular design approach. Education + Training, 54(1), 7-20.

Schulz, B. (2008). The importance of soft skills: Education beyond academic knowledge. Retrieved from http:// ir.polytechnic.edu.na/handle/10628/39

\section{Author}

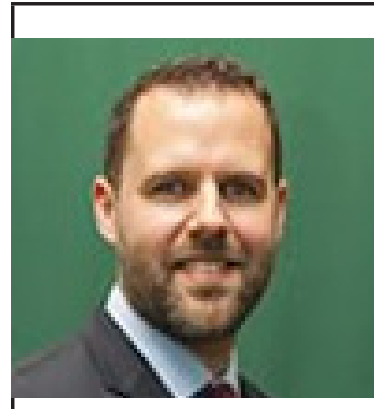

Tres Bishop is director of quality assurance for Comtech Systems Inc. in Orlando, Fla. He handles audit, inspection, quality engineering, and customer/supplier interface functions for the communications solutions company that serves the energy companies in the private sector as well as the U.S. military and foreign governments. Bishop earned a degree in industrial and systems engineering from the University of Florida in Gainesville, Fla. and an MBA and MS in Engineering Management from the Florida Institute of Technology in Melbourne, Fla. He is a Lean Six Sigma Master Black Belt, a Certified Manager of Quality/Organizational Excellence, and a Certified Project Management Professional. Bishop expects to graduate with a Doctor of Business Administration degree from the University of South Florida in 2018. 